\title{
The Commotional Factor in the Etiology of Shell Shock
}

\author{
Interesting Results of Experiments on Animals
}

By Alfred Carver, M. D., Camb.

In the Lancet of Jan. 11th, 1919, Dr. C. S. Myers raises three important questions relating to the problem of "shell shock." The first is as to "the existence of distinct commotional and emotional syndromes" I believe that the following experiments, carried out with the assistance of Lieutenant A. Dinsley, S.A.O.C. prior to the appearance of Dr. Myers's article, will prove of interest as bearing upon this point. The conditions under which "shell shock" arises in man render accurate observations so difficult that experiment upon animals seemed advisable carried out so that the weight of explosive used could be kept constant, its nature and composition known but varied at will, and the ture and composition known but varied at will, and the actual distance of the animals from the centre of de-
tonation measured.

$$
\text { EFFECTS OF HIGH EXPLOSIVES. }
$$

When a high explosive is detonated there arises first a sudden terrific blow which exerts a compressing and shattering force upon its surroundings in every direction. This is instantaneous and is followed immediately by an equally sudden decompression, thirdly rapid oscillatory or vibrating movements are set up, which die down only gradually. Each of the three results requires analysis when considering the effects upon living organisms. A further effect is the purely demoralising effect produced by the vibrations outside the sphere within which any demonstrable physical destruction or injuries occur. Evidence will be adduced to show that the German arranged their shell-fillings so as to enhance this peculiar effect. This, fully in keeping with other of their methods, might be described as "frightfulness by detonation."

If a high explosive be detonated at a point $\mathrm{X}$ thre zones may roughly be mapped out around it, their radii depending among other things, upon the weight of explosive

Zone $\mathrm{A}$ is delimited by the extent of obvious gross disruption, and may be termed "the zone of brisance"; within it a crater is formed, barbed wire and other obstacle are blown aside, broken and distorted; animals are killed and usually lacerated; other high explosives immediately aetonated

Outside this is a second zone, B, which may be termed the "zone of decompression" for the disturbances within it seem mainly attributable to this factor, though coarse shaking movements also play their part. In zone B the grcss effects of shattering and disruption are no longe evident; animals placed in it and protected from flyin fragments rarely show external signs of injury; only sensitive explosives, whose tonal standard is somewhat similar to that of the primary explosive, detonate.

Beyond this can be named a zone, $\mathrm{C}$, in which the effects of detcnation are modified further. The effects upon animals in zone $\mathrm{C}$ vary considerably, but as a rule a short transitory state of stupor is followed by a stage of excitement.

\section{EXPERIMENTS ON FISH.}

Experiments were first carried out in water, the test animals being fish (perch); a depth charge of 6 oz. of selignite was used.

Fish in zone A became obviously "hors de combat," showed gross lacerations, and were sometimes torn in pieces

Fish in zcne B after the detonation floated in an almost vertical position, but slightly inclined with their ventral surfaces uppermost, their mouths just protruding above the surface. At this early stage the whole of their bodies were rigid, and if the fish were pushed down to a depth of about two feet they sank slowly to the bottom of the tank and there remained. The earliest sign of animation was violent and irregular spasmodic movement of the opercula and gills. The first reflex which could be elicited from such fish was erection of the dorsal fin upon stimulation of the skin to either side of it. At the end of about half an hour those fish which eventually recovered began to swim when the abdomen was stroked with a piece of stick, but these first swimming movements carried the fish only forward in a straight line, and no turns were made even when an obstruction was met. The movements were made with the ventral surface uppermost and almost flush with the surface of the water. At this stage, then, the fish had lost their power of equilibraticn, and with this the whole of their orientation in life.

The majority of those which attained the stage of swimming in this way gradually became more active, and eventually, after passing through a side-uppermo posture, began to swim about in a natural manner. In about 12 hours after the detonation all those fish which had not succumbed were, to all áppearances, completely normal.

Dissection of the dead ones showed definite congestion of the foreparts of the brain, hæmorrhagic points in the mid-brain and basal gangliar region, and generally hæmorrhage in the upper region of the spinal cord and medulla. The gills and other viscera, also the muscles attached to the vertebral column, frequently showed areas of hæmorrhage. Dissection of perch taken at random immediately after the detonation either revealed varying degrees of the above-described changes or else, at macroscopic examination, nothing abnormal was discovered.

\section{-}

TO OUR READERS With this issue the career of the SCIEN-
TIFIC AMERICAN SUPPLEMENT
comes to comes to a close and it is succeeded by the
SCIENTIFIC AMERICAN MONTHLY. The change will be more than one of name and period of issue. The new journal will consist of ninety-six reading pages of large
magazine size (nine by twelve inches) and
will include many features which will prove will include \section{$A$ section of the SCIENTIFIC AMERI
CAN MONTHLY will be used as an cial MONTH of the National Research Council} to keep the public informed of the work the Council is doing in organizing scientific research and introducing it into our indus-
tries. The aim of the Council is to make science as important an adjunct of manu
facture in this country as it is in Germany. To further this laudable work we have also arranged with the United States Bureau of Standards to edit a Department in which the splendid research work of this branch of our Government service will be sum-
marized and specially prepared for readers
of the S I E NTIFICAMERICAN
MONTHLY. The National Academy of Sciences will also furnish material describ-
ing the progress of American men of ing the progress of American men of science. Similar arrangements are being
made with certain of the national technical societies so as to keep our readers in touch societies so as to keep our
with the advance of
branches of technology.

We shall continue our policy of publishing the more important announcements of ing the more important announcements of
distinguished technologists, appearing in
foreign as well as domestic publications foreign as well as domestic publications,
thereby reflecting the most advanced thereby refecting the most advanced
thought in science and technology throughout the world. In our columns will be found the complete text of significant European articles, furnishing often the only Engtainable.

Towards the outer margin of $\mathrm{B}$ zone and the inne region of $\mathrm{C}$ zone the effects upon fish could not be sharply differentiated, the severity of the symptoms and the anatomical findings gradually diminishing with the dis tance of the creature from $\mathrm{X}$.

Fish well out in $\mathrm{C}$ zone dashed about vigorously in a disturbed and excited manner, but though their movements were wild and apparently haphazard they generally made away from X. A few came to the surface and splashed about, but when netted no physical abnormality could be demonstrated; and those returned to the wate soon behaved in a completely normal manner.

In considering the effect upon fish of vibrations set up in water one should bear in mind the great developmen in these creatures of special sense organs directly susceptible to stimulation from such. It is conceivable that the effects of the violent vibrations just described are in part due to excessive stimulation of these special sense organs. If this be so, the shock, though still physical, might be more accurately described as of neurogenic than of commotional origin. It is well known that in man lation, the whole ego being swamped by an excessive flood of afferent impulses which gives rise to a condition lood of afferent impulses which gives rise to a condition of neurogenic shock; there being no "commotio."
have no evidence which leads me to think that neurogenic have no evidence which leads me to think that neurogenic
shock of this type plays any appreciable rôle in the production of the war neurnses.

\section{EXPERIMENTS ON MAMMALS}

Experiments with mammals (rats and mice) were carried out on land. Perforated zinc cages were used, partly to fix the position of the animals and partly to protect them from flying fragments. These cages were distributed at measured distances around $X$. The charge was standardised to 3 oz. of explosive.

In zone A cages in and immediately outside the crater formation were simply blown away and distorted, the animals being killed or severely wounded by direct violence; their eyes were bloodshot, and there was often external hæmorrhage from the ear, nose, or mouth. On dissection the alveoli of the lungs were found to be ruptured, and to a variable extent the central nervous system and other viscera showed hæmorrhagic areas. With the effect in A zone we are not further concerned; the change would seem to be due to the direct blow of displaced air, which strikes like a solid substance, and to the effect of the exceedingly rapid decompression succeeding this.

Along the inner part of zone B the findings, though similar to the above, were much less in degree. Animals were invariably rendered unconscious irrespective of the extent or nature of the lesions demonstrable, and occasionally were found to be dead, even though no external injury was present; upon dissection the only abnormal finding, to coarse examination, was general capillary engorgement, especially noticeable in the central nervous system and meninges. Whether this indicates that vasomotor changes play any part in the associated phenomena I am not prepared to say.

Further out in zone B a state of stupor or transitory loss of consciousness, of much shorter duration than in zone A animals, was an almost constant result. During the stage of recovery twitching movements of the limbs were often present, and then the animals. if stimulated by appropriate physical agents, showed massive and exaggerated reflex reactions. For example, the application of a pin-prick to one hinder extremity might be followed either by bilateral contraction of the hinder extremities or even by a generalised convulsion. There was frequently considerable difference in the activity of the reflexes on the two sides of the body-a hemiplegic distributionbut, as a rule, the fore-limbs were more severely affected than the hind and showed weakness and dragging after the latter had recovered normal movements. Reflex responses, though vigorous, died away quickly, but were often succeeded by a weaker repetition even when no
fresh stimulus was given. Rapid fatigue of the response on repeated stimulation was a noticeable feature By dissection no gross macroscopical evidence of internal injury to such animals was revealed, but capillary engorgement, as in animals nearer $\mathrm{X}$, was generally demonstrable.

Animals left alone after this stage had been reached gradually began to behave in a more normal manner, though for a considerable time their conduct, postures, and gaits were awkward. The severity of these disorders varied greatly from animal to animal, which rendered it impossible to deliminate, from biological observations, the precise boundaries of the several zones. Speaking generally the effect diminished gradually in proportion to the distance of the animal from $\mathrm{X}$.

For some distance beyond what I have termed the C zone, animals crouched down and huddled themselves together whenever a detonation took place; after this state of diminished activity a state of apparent excitement with increased restlessness was the rule. Animals left exposed in this position during a series of experiments invariably crouched down as flat as possible and seemed to be in an absolutely stuporose condition. When liberated they made no effort to run away but remained for a long time in a huddled-up posture. The interpreficult. Should fear be allowed as the cause or are other more material factors also at work?

If instead of employing a single explosive at $\mathrm{X}$ one If instead of employing a single explosive at $\mathrm{X}$ one became more pronounced, but the increased effect was particularly noticeable in zone $\mathrm{C}$ and its immediate surroundings.

OBSERVATIONS ON SOLDIERS.

In this connexion it is of interest to record some observations carried out upon physically and mentally fit men of an "Ammunition Proof and Demolition Section" during the ordinary course of their duties. The staff, drawn from infantry-men with some technical knowledge (Continued on page 388) 


\title{
The Mangroves of Tropical America
}

\author{
A Little Known Factor of Much Value in Our Commercial Geography
}

By C. D. Mell

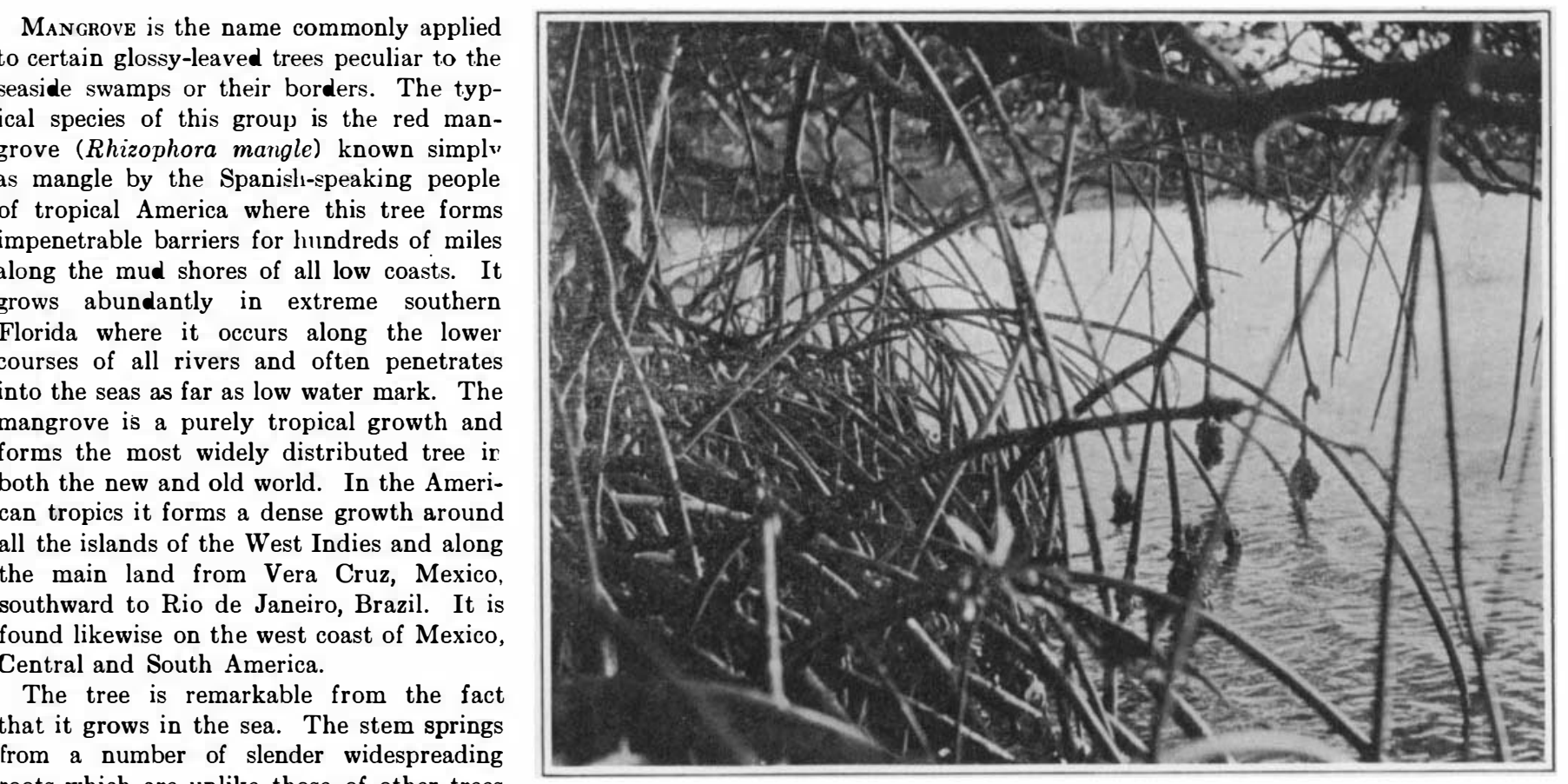

rom a number of slender widespreadin roots which are unlike those of other trees in that they develop above the ground for five or six feet and curve outward and downward into the mud forming a series

of arches. The growth of these roots is so dense that tanning material and large quantities are imported anit is practically impossible to pass through parts of nually for this purpose. The bark, which is from three-

these mangrove swamps. It is, therefore, very difficult fourths to one inch thick, of a dull reddish color, someto operate in these forests to the out the logs or the bark which represents its chief commercial product.

The trees in many parts develop large dimensions. The average tree is from 60 to 80 feet in height at naturity and from one to three feet in diameter. Th wood is very strong and hard, bears the water well, and is much used in parts of the West Indies for knees and ribs of boats for which the archings and angles of its limbs naturally adapt it. The forests of this species were at one time exploited in Southern Florida in the vicinity of Cape Sable, but it was too expensive to transport the logs and bark to the boat landing. The logs were cut into boards for use in flooring and interior trim. In Ecuador most of the houses along the coast are built of mangrove wood and practically all wharve are constructed of it for which it is highly esteemed. Its principal uses are for fuel and charcoal.

Red mangrove produces the bulk of the commercia bark used for tanning purposes. It is much prized as a what fibrous and covered with a grayish cork-like cuticle, contains tannin superior to that of many other barks used for that purpose. Its color is of a rather deep red which is cited as an objection to its being brought into still greater use. The Bulletin of the Imperial Institute (London), Vol. No. 4, 1907, page 346, as 36 per cent.

The gathering of the bark is an exceedingly difficult undertaking, and the work is attended by many hardships. Work commences at the beginning of the growing season (wet season), when the bark can be removed readily from the trunks of the trees felled. The dense growth in the mangrove forest makes felling difficult, but and transported to a central station where the whitish outer layer is removed by means of a machete. This states that mangrove bark contains 25 per cent. of tannin, while some authorities claim that it runs as high after the tree is down the bark is removed from the trunk and is carried by men to the small boats (dugouts) facilitates drying considerably and in. so doing fully 50 per cent. of the weight is lost. The pieces are usually about four feet long and from six inches to a foot wide in which form it is stacked up like cordwood. When it is dry and ready for the market the bark is broken up into small pieces so as to facilitate packing it in bags for export. Great care is taken not to allow the broken or cut pieces to become wet or to absorb too much moisture after it has been put in bags and is ready for shipment. The prices at source of origin vary considerably depending upon the quality. The present prices are ruling high, but during normal times one cent per pound is considered a good price in the tropics. In some parts of Brazil good quality bark has been sold recently as high as 5 cents per pound f.o.b. shipping port.

During 1917 the total quantity of mangrove bark imported from all parts of the tropics amounted to 10,565 tons, valued at $\$ 297,897$. Of this amount 2,524 tons came from the American tropics, chiefly Venezuela, while the remainder, 8,041 tons, originated chiefly in Portuguese West Africa. The supply of mangrove bark in tropical America is unlimited and there is no ason why the industry should not be greatly developed. Instead of drawing four-fifths of our requirements from far off southern Africa the American importers and users should look to the south of us for their raw material where it is closer at hand. Moreover, we owe it to our tropical American neighbors to help develop their natural resources.

\section{The Commotion Factor in the} Etiology of Shell Shock (Continued from page 378 )

was sheltered in a well-protected dug-out about 100 yards from $X$, the centre of detonation. In this case $X$ was a large crater formed in the centre of the demolition ground, and contained the official maximum weight for each single destruction-viz., $200 \mathrm{lb}$.

Although the men had some technical knowledge they did not know the nature of the explosive fillings which were to be destroyed on any given occasion, and it was interesting to study the differing effects of these upon them. Simple single fillings, such as T.N.T., picric acid,

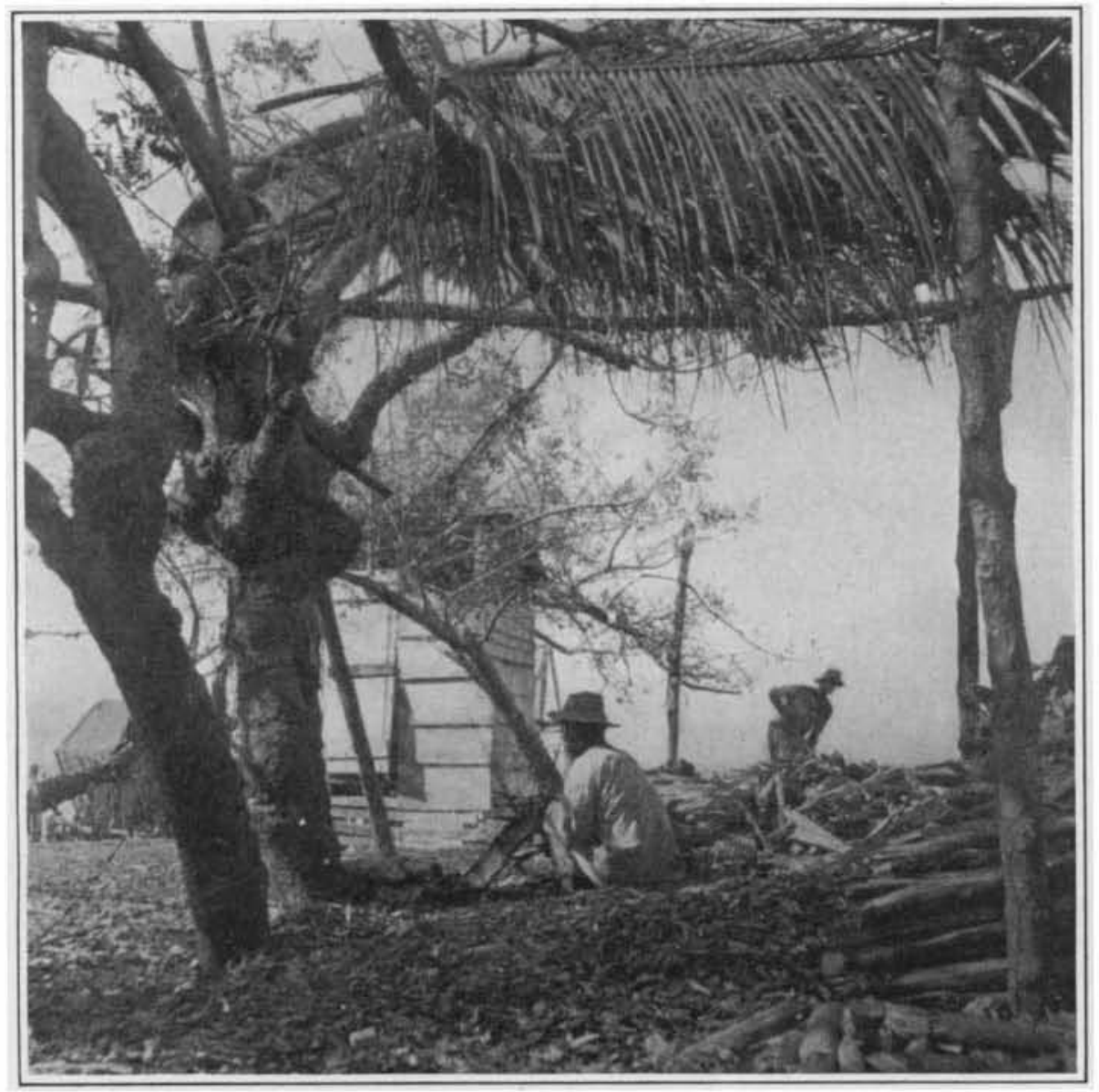

Removing with a machete the corky outer portion of the bark

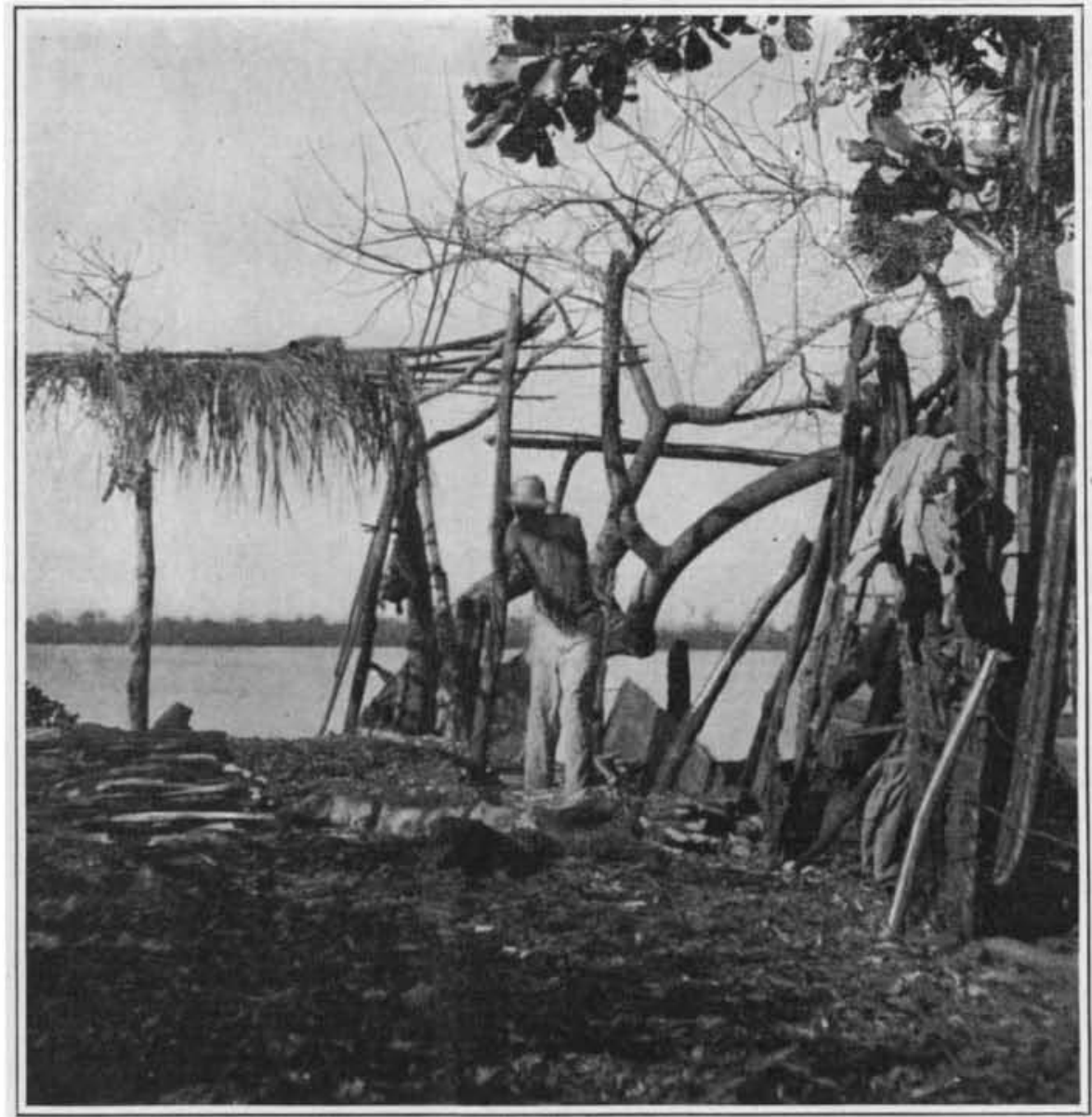

Cutting up the logs for fuel after recovery of the bark 


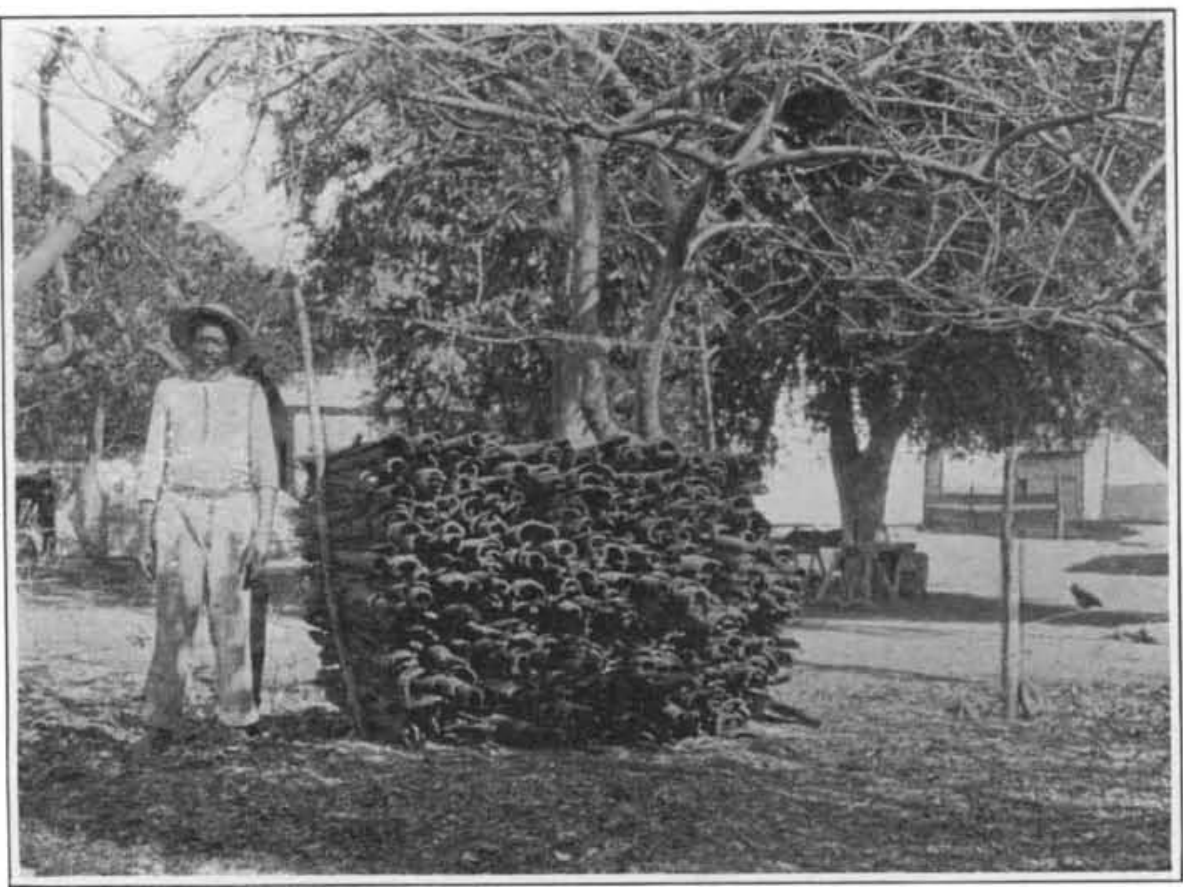

Red mangrove bark ready for the market

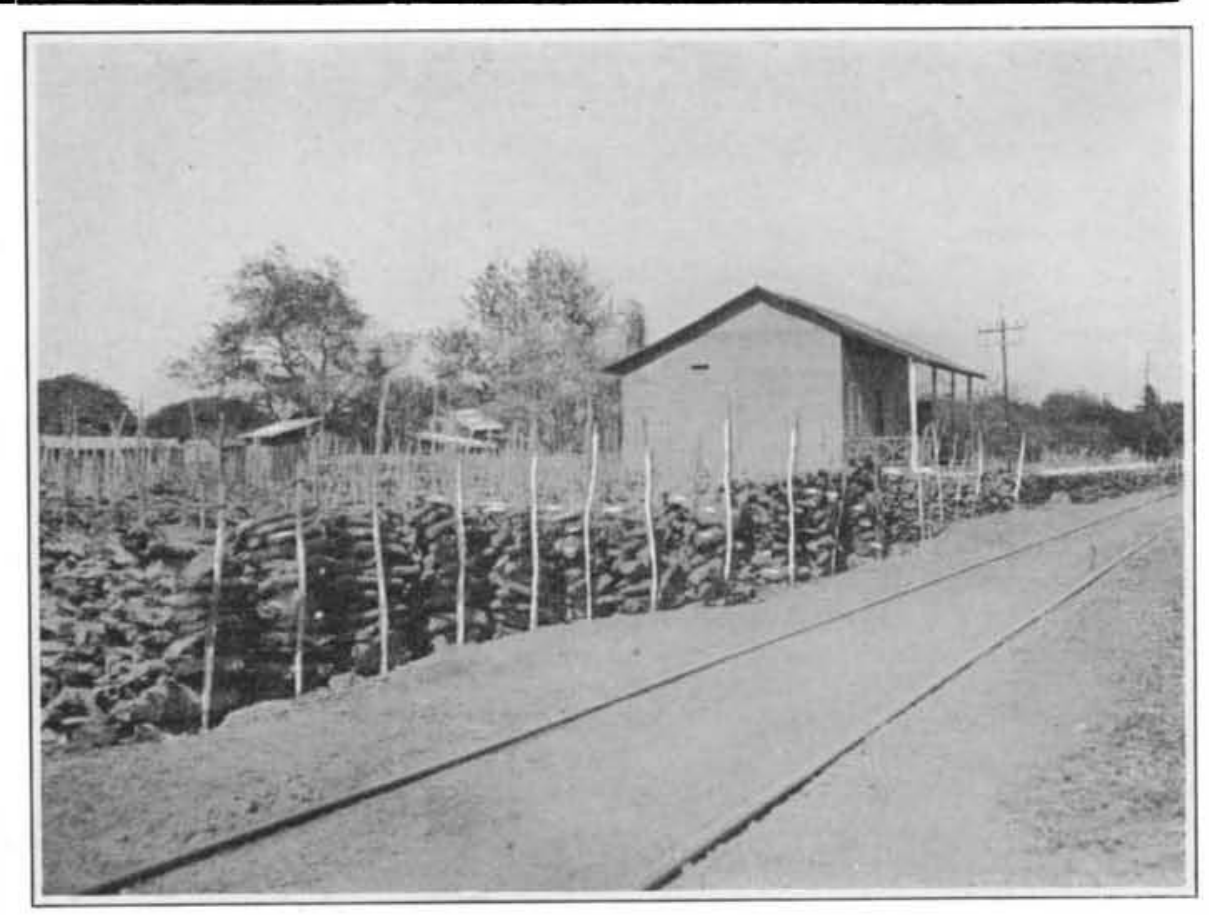

The red mangrove fire wood of the tropical American coast and tetryl, rarely caused any of the men discomfort under the conditions described, yet when mixtures such as ammonal (British), amatol (British and German), donarit and glïckauf (German) were detonated many of the men complained of unpleasant sensations--e.g., "catching in the throat," "peculiar feelings in the chest," "creepy feelings down the spine," or "weakness of the legs"; other were seen to shake violently and the rate of their pulse and respiration increased.

When separated or layered fillings of different explosives having widely differing velocities of detonation were demolished the effects became greater and several of the men passed into a stuporose condition, followed in some instances by violent shaking and twitching, and in one case by vomiting.

Men thus affected were not fit for duty for the next two or three days, and even then, although fully aware that no real danger attended the demolitions, they seemed to be in a state of mental anxiety and were more readily affected by detonations than perviously.

EFFECTS OF DETONATIONS OF SHELLS WITH LAYERED FILUNGG.

Examination of German shells shows that in certain o them layered fillings were deliberately employed, although involving more time and labor. Captured German documents reveal the fact that this type of shell was intended for use immediately prior to an attack, and in sector where the opposing troops were well entrenched. Hence we must infer that the Germans were aware of the peculiar demoralising effects which attend the detonation of these mixed and layered fillings.

Most of those who have been through a severe German bombardment bear witness to the demoralising effect it had upon them, and state how this was succeeded, owin to summation of effect as the bombardment continued by a sort of "fixed glassy feeling" even when the shell did not detonate particularly close to them. In order to eliminate as far as possible, if not entirely, the psychic eliminate as far as possible, if not entirem, the psychic factor which in such cases plays its part it is instructive to study cases in which the detonation fell like a "bolt
from the blue" upon individuals who were not in a state from the blue" upon individuals who were not in a state
of tense expectation or fatigue at the moment of the

of tense

At the same time one cannot ignore the importance of the predisposing factors, which are highly complex. There is, however, nothing distinctive about them as regards the type of neurosis developed. So far as my observations go the most important of them-viz, fatigue both physgo the most important of them-viz., fatigue both physical and mental-seem to operate in a general way by
lowering the resistance of the individual to all forms of shock, though naturally the individual of poor make-up is more profoundly affected than the robust type.

\section{COMMOTION FROM "DIRECT CONCUSSION."}

First to deal with the syndrome in cases where commotion resulting from "direct concussion" without wounding, as in animals exposed in the B zone, is the primary causal factor.

The initial symptom is unconsciousness, of ten of several hours' duration and possibly persisting for days. Consciousness when first recovered does not remain clear, but the patient passes through a stage of variable duration during which he loses and regains it-the so-called "dipping of consciousness." Some degree of aphasia and sphincter troubles are common at this stage, which is fre- quently associated with an active delirium in which the patient re-enacts episodes of his military service.

At this time the general condition is one of extreme exhaustion; all mental operations are sluggish and there is great difficulty of concentration. Amnesia both for immediate and remote past is a common occurrence. The voice is of ten altered, becoming slow, monotonous, and higher pitched than normally. In severe cases these symptoms tend to persist for many months, and relapses are easily induced by any form of fatigue.

Clinically the importance of recognising these symptoms is that the prognosis in such cases is much graver toms is that the prognosis in such cases is much graver than in those giving an exaggerated account of events
after they had been thrown down or partially buried. In cases exhibiting the above symptoms prolonged rest, with freedom from strain of all sorts, is essential. Psychotherapeutic treatment is of little avail except in so far as fixation of symptoms may have occurred in the later stages.

"INDIRECT CONCUSSION."

Cases of "indirect concussion" corresponding to animals on the borders of the $\mathrm{B}$ and $\mathrm{C}$ zones demand mor careful discrimination. The history is complicated by the fact that there is a tendency on the part of the patient to exaggerate, but careful questioning will overcome this difficulty.

Unconsciousness or stupor of comparatively brief duration is the rule, and the phenomenon of "dipping of con sciousness" is not observed. Active delirium is rare, and is not of the occupational type. Amnesia though frequently present is only retrograde, is less extensive, and more readily recovered than in the type of case previously described.

The severity of the symptoms, as well as their duration is also less, but there is a greater tendency to the superimposition of functional troubles such as paralyses and algesias; these may supervene immediately but, mor commonly, they develop later in the course of the disease when the symptoms of commotional origin are recovering. If they are removed by appropriate treatment th patient, after a few weeks' complete rest, generally feel as well as ever. Easy fatigability and diminished powe to concentrate the attention are apt to be more persistent symptoms, and although the patient declares himsel "quite fit," it is advisable to insist upon a more prolonged period of rest.

\section{"THE LAST STRAW"}

Cases in which the neurosis arose as the result of exposure to shell fire in what $I$ have referred to as the $C$ one are naturally much more difficult to differentiate from those of purely psychogenic origin, and it cannot be said that they are recognisable by a distinctive syndrome. The description already given of men so exposed in th "Ammunition Proof and Demolition Ground" affords a better picture of the onset of the neurosis than can bo got from an analysis of the more complicated condition arising during trench warfare.

In a rather disparaging way any shell detonating out side the A zone is commonly referred to as merely "the last straw," its influence being thus tacitly attributed to purely emotional factors. It is, nevertheless, a last straw which cannot be lightly disregarded, and one is justified in maintaining that a sufficient number of such "straws" will cause the downfall even of the most robust.

It should be remembered that the stability of any explosive is under these conditions diminished, and its sensitiveness so raised that it may eventually detonate. There is no difficulty, then, in conceiving that physical processes, which cause alterations in the direction of instability in a relatively simple chemical compound such as an explosive, may, in a similar way, affect the far more delicate colloidal solutions contained in the central nervous system.

COMBINATION OF PHYSICAL AND EMOTIONAL CAUSES.

With cases of purely psychogenic origin, many of whom never reach the danger zone, it is not my purpose to deal. The syndrome closely resembles that with which we are familiar in civil life, though the "current conflict" is usually of a different nature. Psychological analysis reveals the repression and the conflict which is being shirked.

The point which seems to have been universally overlcoked is that under the conditions of modern warfare the soldier is constantly subjected both to physical and emotional causes of shock, and that the two factors operate in conjunction. Also whichever factor be in any given case the primary one the individual, once sensitized by either, remains for a long time, perhaps always, hypersensitive to both forms of stimulation, and a vicious circle is thus established.

Although one not infrequently meets with cases in which apparently a single factor has been operative, a careful study of histories in the special military neurological hospitals has led me to conclude that the combined action of the two xtiological factors is much the more common event. If this be so, it is not surprising that those who expect to find either definite commotional or emotional syndromes in the bulk of their patients are generally disappointed.

\section{CONCLUSION}

I have tried with the aid of the experiments, here briefly set forth, to give a picture of the early syndrome which distinguishes the more severe cases of commotional shock, but as the experiments themselves no less than clinical experience indicates, the symptoms in slighter cases become almost inextricably blended with others which appear identical with those resulting from emotional shock. Hence, though at the two extremes one may with ease deduce the nature of the primary pathogenic factor from a study of the syndrome exhibited, this becomes increasingly difficult as one approaches the intermediate members of the series, and one's judgment is largely determined by the aspect from which one approaches the problem.

\section{The Use of Water for Rock Blasting.}

A WrITER in Zeitschrift für Schiesswesen describes a hydraulic device for blowing up rocks, and, in particular for demolishing bridge piles and ferro-concrete foundations. It is based on the principle of the hydraulic press; enormous pressures are set up within the rock, which eventually bursts. The pressure is transmitted by a pipe-line to a cylinder $85 \mathrm{~mm}$. diam. in which eight pistons may be successively displaced telescopically. The cylinder is inserted into a hole, drilled by an electric drill in the rock to be blown up. The pistons bury themselves in the rock one after another and blow up the rock. The holes take 10 to 15 minutes to drill (they are about $2.5 \mathrm{~cm}$. deep), and in 5 minutes after that the rock is shattered. It is said that this device has proved successful in mines and quarries where the use of explosives would be dangerous. From The Technical Review. 